Port Econ J (2017) 16:17-48

DOI 10.1007/s10258-016-0126-5

\title{
Determinants of capital flows to emerging and advanced economies between 1990 and 2011
}

Grzegorz Tchorek ${ }^{1}$ (D) \& Michał Brzozowski ${ }^{2}$ \&

Paweł Śliwiński ${ }^{3}$

Received: 16 March 2016 / Accepted: 20 December 2016/Published online: 16 January 2017

\# ISEG 2017

Abstract The previous and latest crises confirmed that stability of external financing of the economy is determined not only by the volume of capital inflow but also by its structure. It is established that a bias in gross external liabilities towards debt, especially short-term, may rise vulnerability to financial crises. Greater share of equity capital, mainly direct investment is not found to bear such financial risk. The results of Bayesian Model Averaging (BMA) show that influence of variables inherent in macroeconomic and portfolio approaches varies depending on the type of capital inflow and the group of countries. We also find some arguments that equity investment is a more desirable form of foreign capital because debt inflows are more responsive to global factors and therefore more volatile. As a word of caution, we highlight the need for diversification and careful monitoring of external financing sources and forms.

Keywords Capital flows $\cdot$ FDI $\cdot$ Portfolio and banking capital flows $\cdot$ Push-pull factors

JEL classification $\mathrm{F} 21 \cdot \mathrm{F} 32 \cdot \mathrm{G} 11$

Grzegorz Tchorek

Grzegorz.Tchorek@nbp.pl

1 National Bank of Poland, University of Warsaw, Warsaw, Poland

2 University of Warsaw, Warsaw, Poland

3 Poznań University of Economics and Business, Poznań, Poland 